\title{
PRODUÇÃO DE ENZIMAS CELULOLÍTICAS FÚNGICAS POR FERMENTAÇÃO EM ESTADO SÓLIDO
}

\author{
T. M. R SOUZA ${ }^{1}$, J. C. THOMÉO ${ }^{2}$, F. P. CASCIATORI ${ }^{3}$ \\ ${ }^{1}$ Universidade Federal de São Carlos, Centro de Ciências da Natureza \\ ${ }^{2}$ Universidade Estadual Paulista, Departamento de Engenharia e Tecnologia de Alimentos \\ ${ }^{3}$ Universidade Federal de São Carlos, Departamento de Engenharia Química \\ E-mail para contato: thamimrs@outlook.com
}

\begin{abstract}
RESUMO - Neste trabalho, propôs-se obter, por fermentação em estado sólido (FES), enzimas que possam ser aplicadas na hidrólise de biomassa lignocelulósica. O fungo termofílico Myceliophtora thermophila I-1D3-b foi cultivado em farelo de trigo e em serragem de madeira, resíduos agroindustrais abundantes no território em que se situa o campus Lagoa do Sino da Universidade Federal de São Carlos (UFSCar). Foram testados diferentes tamanhos de partículas e teores de umidade dos substratos. Não houve desenvolvimento do fungo na serragem de madeira, mas o farelo de trigo proporcionou condições adequadas ao crescimento do fungo e à produção de enzimas celulolíticas. Foram analisadas as atividades dos extratos obtidos, tendo-se concluído que o tamanho de partícula e o teor de umidade não influenciaram significativamente as atividades de endoglucanase e de papel de filtro dos extratos. Ademais, os extratos obtidos do cultivo do fungo em farelo de trigo apresentavam valores interessantes de atividade papel de filtro.
\end{abstract}

\section{INTRODUÇÃO}

Neste momento de discussão da matriz energética mundial e de busca por fontes de energia limpas e renováveis, as enzimas celulolíticas chama atenção da comunidade científica e industrial tendo em vista sua aplicação na hidrólise de materiais lignocelulósicos na cadeia de produção de etanol de segunda geração. Tal denominação vem do fato de o etanol de segunda geração ter como matéria-prima açúcares provenientes da quebra das cadeias de celulose e hemicelulose que advém de biomassa residual, tais como caules, folhas, cascas, farelos e bagaços, que são sobras da agroindustrias, já que o produto primário de interesse já fora extraído.

Tendo em vista que a base da economia da região em que se situa o campus Lagoa do Sino da UFSCar é agro-madeireira, com destaque para a produção de grãos, dentre estes o milho e trigo, e de madeiras, dentre estas pinus e eucalipto, destacam-se como rejeitos dessas agroindustrias a palha de milho, o farelo de trigo e a serragem de madeira, respectivamente. Dos carboidratos na casca e no farelo de trigo, aproximadamente 34 e $32 \%$ são de celulose e hemicelulose, respectivamente, longas cadeias de glicose que podem ser quebradas para fornecer açúcares para a cadeia de produção de etanol de segunda geração. Considerando-se que $50 \%$ dos resíduos de trigo estariam disponíveis para a conversão, mais de 600 milhões de litros de etanol podem potencialmente ser produzidos (FERREIRA-LEITÃO et al., 2010). 
A produção de etanol de segunda geração, também chamado de bioetanol ou etanol celulósico, envolve três etapas principais: pré-tratamento da biomassa vegetal, hidrólise da celulose e da hemicelulose e fermentação dos açúcares liberados. A hidrólise ou sacarificação pode ocorrer pelas vias enzimática ou química. A hidrólise enzimática apresenta diversas vantagens sobre a química, dentre as quais se devem destacar o menor gasto energético e a alta especificidade pelo substrato, evitando a produção de compostos indesejáveis. As principais enzimas envolvidas neste processo são as celulases, nome genérico usado para designar uma classe de enzimas que atuam conjuntamente na quebra da celulose a glicose, sendo constituídas por endoglucanases, exoglucanases e $\beta$-glucosidase (PINTO, 2010).

No entanto, a via enzimática é mais lenta e tem como uma das principais barreiras processos eficientes e viáveis de produção de enzimas a custo que viabilize seu uso (MISHIMA et al., 2006). Uma alternativa que vem sendo estudada para a produção dessas enzimas a serem aplicadas na hidrólise da biomassa lignocelulósica é a fermentação em estado sólido (FES), uma vez que este processo permite obter tais enzimas também a partir de rejeitos agroindustriais, o que pode ser tanto econômica quanto ambientalmente interessante.

A fermentação em estado sólido (FES) pode ser definida como o crescimento de microrganismos sobre partículas sólidas úmidas, sem que água líquida preencha o espaço entre partículas (MITCHELL et al., 2006). Devido às atividades de água mais baixas nos sistemas de FES, os microrganismos que mais se adaptam a esse cultivo são os fungos filamentosos, dentre os quais os termofílicos se destacam por produzirem enzimas mais termoestáveis, característica bastante interessante do ponto de vista industrial da produção do etanol de segunda geração, sobretudo quando pré-tratamento a quente são empregados (DA SILVA et al., 2005).

Em trabalhos anteriores do grupo de pesquisa do Ibilce/UNESP, foi isolado o fungo termofílico Myceliophtora thermophila I-1D3b (ZANELATO et al., 2012), que já se mostrou como bom produtor de enzimas celulolíticas quando cultivado em uma mistura de bagaço de cana e farelo de trigo (ZANELATO et al., 2012; CASCIATORI et al., 2013). Tendo em vista os bons resultados obtidos com bagaço de cana, acredita-se haver potencial para utilização de outros rejeitos sólidos agroindustriais ricos em lignocelulose como substratos para FES. Diante do exposto, o emprego de farelo de trigo e serragem de madeira como substratos para o cultivo do fungo termofílico $M$. thermophila para obtenção de enzimas por FES mostra-se como alternativa biotecnológica relevante e sustentável.

\section{MATERIAIS E MÉTODOS}

O projeto encontra-se em desenvolvimento nos Laboratórios de Engenharia do Centro de Ciências da Natureza do campus Lagoa do Sino da UFSCar.

\subsection{Microrganismo e substratos}

Foi empregado como agente fermentativo o fungo filamentoso termofílico Myceliophtora thermophila I-1D3b, que fora isolado por Zanelato et al. (2012) e demonstrou produzir altas atividades celulolíticas em escalas de frascos e de reator de bancada. $\mathrm{O}$ fungo pertence à UNESP e foi gentilmente cedido para os ensaios deste projeto por intermédio do Prof. Dr. João Cláudio Thoméo (DETA/IBILCE/UNESP). Como substratos foram empregados farelo de casca de trigo e serragem de madeira. Ambos os substratos foram obtidos na própria Fazenda Lagoa do Sino. 
Esses substratos passaram por processos de peneiramento, trituração, secagem e esterilização em autoclave antes de serem utilizados. Para fermentação, os substratos foram inoculados com uma suspensão de esporos do fungo e os teores de umidade foram acertados com adição de solução nutriente, após o que o meio foi homogeneizado e incubado.

\subsection{Ensaios fermentativos em embalagens de polipropileno}

Os ensaios fermentativos foram realizados em embalagens de polipropileno de 11 x 19,5 $\mathrm{cm}$, e em cada saco plástico foram colocados $5 \mathrm{~g}$ de substrato sólido seco inicial. Foram empregados farelo de trigo e serragem de madeira com duas granulometrias e dois teores de umidade.

No momento de ínicio dos ensaios fermentativos, a suspensão fúngica foi inoculada e a umidade do material foi acertada com solução nutriente com $\mathrm{pH}=5$. Os sacos fermentativos foram incubados em câmara DBO a $45^{\circ} \mathrm{C}$ por 96 horas (ZANELATO et al., 2012). Ao final do tempo de cultivo, a extração das enzimas foi feita por adição de água destilada $(20 \mathrm{~mL}$ por grama de substrato seco) e revolvimento manual. $\mathrm{O}$ extrato foi filtrado e foi tomado como solução enzimática bruta para os testes de atividades enzimáticas.

\subsection{Determinação das atividades enzimáticas dos extratos brutos obtidos por FES}

Foram determinadas as atividades endoglucanase (CMCase) e papel de filtro ou FPA dos extratos enzimáticos brutos (PINTO, 2010; CASCIATORI et al., 2013). Com base no volume de água utilizado para extração das enzimas, os resultados das atividades enzimáticas foram convertidos para serem expressos em unidades por grama de substrato sólido.

\section{RESULTADOS E DISCUSSÕES}

Na Tabela 1, são apresentados os resultados das atividades enzimáticas obtidas nos ensaios de FES nos dois substratos empregados e com dois níveis de granulometria e conteúdo de umidade, conforme planejamento experimental fatorial $2^{2}$. As atividades CMCase e FPA estão expressas em unidades de atividade enzimática por grama de substrato sólido seco inicial, sendo o resultado apresentado dado pela média das triplicatas, acompanhadas dos respectivos desvios padrão.

Tabela 1. Atividades enzimáticas obtidas por FES.

\begin{tabular}{|c|c|c|c|c|}
\hline Material & $\begin{array}{c}\text { Tamanho de } \\
\text { partícula }(\mathrm{mm})\end{array}$ & $\begin{array}{l}\text { Teor de umidade } \\
\text { (\% em base úmida) }\end{array}$ & $\begin{array}{l}\text { CMCase } \\
\text { (U/gss)* }\end{array}$ & $\begin{array}{c}\text { FPA } \\
(\mathrm{U} / \mathrm{gss})^{*}\end{array}$ \\
\hline \multirow{4}{*}{$\begin{array}{l}\text { Serragem } \\
\text { de madeira }\end{array}$} & \multirow[t]{2}{*}{1} & 65 & \multirow{4}{*}{\multicolumn{2}{|c|}{ Não ocorreu crescimento do fungo }} \\
\hline & & 75 & & \\
\hline & \multirow{2}{*}{6} & 65 & & \\
\hline & & 75 & & \\
\hline \multirow{4}{*}{$\begin{array}{l}\text { Farelo de } \\
\text { trigo }\end{array}$} & \multirow{2}{*}{2} & 65 & $17,8 \pm 0,6$ & $4,2 \pm 0,5$ \\
\hline & & 75 & $18,3 \pm 4,0$ & $4,5 \pm 0,4$ \\
\hline & \multirow{2}{*}{6} & 65 & $19,0 \pm 4,30$ & $4,8 \pm 1,0$ \\
\hline & & 75 & $18,9 \pm 1,8$ & $5,4 \pm 0,5$ \\
\hline
\end{tabular}

*U/gss = Unidades de atividade por grama de substrato sólido seco; média \pm desvio padrão. 
$\mathrm{Na}$ serragem de madeira, para ambas as granulometrias e ambos os conteúdos de umidade, não ocorreu crescimento do fungo Myceliophthora thermophila. Como não fora observado nenhum sinal de colonização da serragem pelo fungo, não foi feita extração. Considerando que o fungo secreta enzimas visando a obter nutrientes para seu metabolismo, infere-se que muito provavelmente não houve crescimento devido à não produção de enzimas, uma vez que o metabolismo do fungo não foi induzido por dificuldade de acesso ao substrato altamente complexo fornecido.

Segundo Brito et al. (2014), os constituintes químicos da madeira podem ser divididos em dois grupos: compostos de alto peso molecular (estruturais) e de baixo peso molecular (não estruturais). De acordo com Rowell (2005), os compostos de alto peso molecular englobam celulose e hemiceluloses ( 65 a $75 \%$ ) e lignina (18 a $35 \%$ da massa seca de madeira). Machado, Zangirolami e Adriano (2009) estudaram a obtenção de etanol a partir de polpa de celulose branqueada e serragem, derivados do processamento de eucalipto para produção de celulose. Mesmo tendo submetido a serragem a pré-tratamentos para remoção de hemicelulose e lignina, os autores concluíram que a serragem não fora efetivamente hidrolisada pela enzima comercial de alta atividade celulolítica empregada naquele trabalho. Isso indica que a parede celular da serragem, por ser muito bem estruturada, é muito recalcitrante à ação enzimática, mesmo após diferentes pré-tratamento. Da mesma forma, no presente trabalho, a serragem de madeira não forneceu condições ao desenvolvimento do fungo, sobretudo por não ter passado por nenhum pré-tratamento. Na etapa seguinte deste trabalho, podem-se esperar melhores resultados na hidrólise de serragem pré-tratada do que na de serragem in natura.

Por outro lado, no farelo de casca de trigo, houve colonização do material e foi possível observar visualmente o crescimento do fungo em seu aspecto branco cotonoso, propiciado pela riqueza nutricional deste resíduo do processamento dos grãos de trigo (SLAVIN, 2003). De acordo com análise estatística dos resultados, realizada com auxílio do software livre Chemoface v1.5 (UFLA, Lavras-MG, Brasil), não houve efeito significativo $(\alpha=0,05)$ das variáveis tamanho de partícula e conteúdo de umidade para atividades de CMCase e FPA, nem efeito de interação entre as variáveis, conforme pode ser verificado nos gráficos de pareto apresentados na Figura 1. Além disso, observou-se que as atividades CMCase foram relativamente baixas, mas a atividade FPA foi satisfatória, em comparação com dados da literatura, como pode ser visto na Tabela 2.

Embora as atividades CMCase tenham sido baixas, os extratos enzimáticos apresentaram alta atividade FPA, que por usa vez expressa a atividade conjunta das três principais enzimas do complexo celulolítico, a saber endoglucanase, exoglucanase e betaglicosidase (PINTO, 2010), o que pode indicar que o extrato é bem balanceado nos três tipos de enzimas principais, podendo ser eficiente para sacarificação de biomassa lignocelulósica. Não tendo havido influência significativa do tamanho de partícula nem do conteúdo de umidade, não convém aplicar modelos de regressão. Além disso, pode-se definir como mais conveniente empregar o tamanho de partícula de $6 \mathrm{~mm}$, uma vez que custos de trituração do material e/ou uma etapa de peneiramento são dispensados; quanto ao conteúdo de umidade, o emprego da menor umidade é interessante pois restringe ainda mais as possibilidades de contaminação por bactérias e outros fungos, tornando o processo mais robusto em termos de assepsia e riscos microbiológicos. 
Figura 1. Gráficos de pareto das atividades: (a) CMCase; (b) FPA.

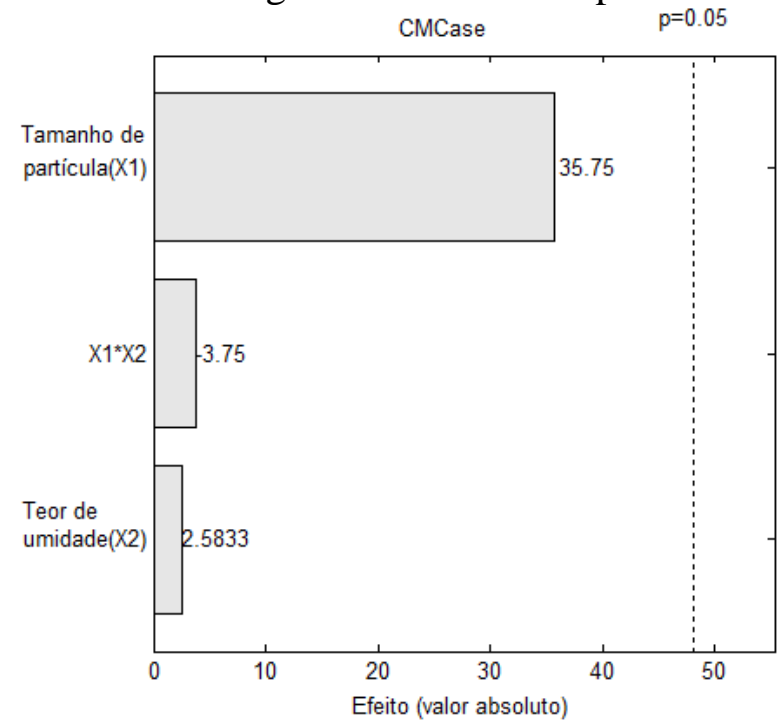

(a)

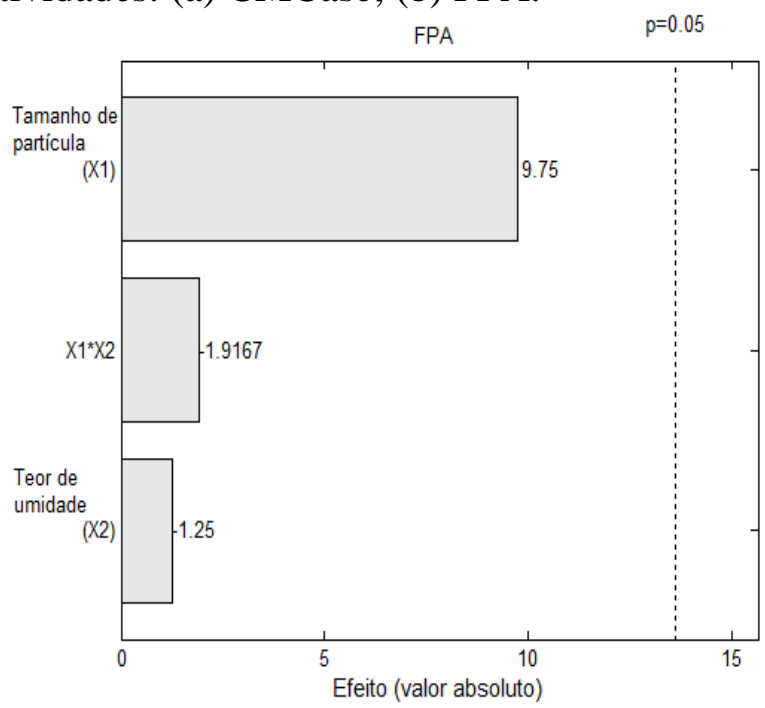

(b)

Tabela 2. Atividades CMCase e FPA obtidas por FES reportadas na literatura.

\begin{tabular}{|c|c|c|c|c|}
\hline Microrganismo & Substrato* & $\begin{array}{l}\text { CMCase } \\
\text { (U/gss) }\end{array}$ & $\begin{array}{l}\text { FPA } \\
\text { (U/gss) }\end{array}$ & Referência \\
\hline Myceliophthora sp. (V2A2) & PA & 31 & 0,6 & \multirow{3}{*}{$\begin{array}{l}\text { Soni et al. } \\
(2008)\end{array}$} \\
\hline Myceliophthora fergusii (T41) & PA & 37 & 2,3 & \\
\hline Myceliophthora sp. (MYC) & PA & 35 & 2,4 & \\
\hline Myceliophthora sp. (IMI 389099) & $\mathrm{BC}$ & 7 & 0,7 & \multirow{2}{*}{$\begin{array}{l}\text { Badhan et al. } \\
(2007)\end{array}$} \\
\hline Myceliophthora sp. (IMI 389099) & FT & 27 & 0,7 & \\
\hline Myceliophthora sp. M.7.7 & $\mathrm{BC}+\mathrm{FT}$ & 54 & 2,0 & $\begin{array}{l}\text { Moretti } \\
\text { (2010) }\end{array}$ \\
\hline Myceliophthora thermophila I-1D3b & FT & 19 & 5,4 & Este trabalho \\
\hline
\end{tabular}

* PA: Palha de arroz; BC: Bagaço de cana; FT: Farelo de trigo.

\section{REFERÊNCIAS}

BADHAN, A. K.; CHADHA, B. S.; KAUR, J.; SAINI, H. S.; BHAT, M. K. Production of multiple xylanolytic and cellulolytic enzymes by thermophilic fungus Myceliophthora $s p$. IMI 387099. Bioresource Technology, v. 98, p. 504-510, 2007.

BRITO, R. F. de; STANGERLIN, D. M.; CALEGARI, L.; PARIZ, E.; CALEGARI, C. C. A.; GATTO, D. A. Influência da variação axial, radial e granulométrica da serragem na composição química da madeira de jurema-preta. Ciência da Madeira (Brazilian Journal of Wood Science), v. 5, n. 2, p. 111-117, 2014.

CASCIATORI, F. P.; CASCIATORI, P. A.; THOMÉO, J. C. Cellulase production in packed bed bioreactor by solid-state fermentation. In: European Biomass Conference and Exhibition Proceedings, p. 1539-1546, 2013. 
DA SILVA, R.; LAGO, E. S.; MERHEB, C. W.; MACCHIONE, M. M.; PARK, Y. K. Production of Xylanase and CMCase on Solid State Fermentation in Different Residues by Thermoascus aurantiacus Miehe. Brazilian Journal of Microbiology, v. 36, p. 235 - 241, 2005.

FERREIRA-LEITAO, V. et al. Biomass Residues in Brazil: availability and potential uses. Waste Biomass Valor, v. 1, p. 65-76, 2010.

MACHADO, A. de T.; ZANGIROLAMI, T. C.; ADRIANO, W. S. Obtenção de etanol a partir de derivados do processamento do eucalipto para produção de celulose por sacarificação e fermentação simultâneas. VIII Congresso Brasileiro de Engenharia Química em Iniciação Científica, Uberlândia-MG, 2009.

MISHIMA, D.; TATEDA, M.; IKE, M.; FUJITA, M. Comparative study on chemical pretreatments to accelerate enzymatic hydrolysis of aquatic macrophyte biomass used in water purification processes. Bioresource Technology, v. 97, p. 2166-2172, 2006.

MITCHELL, D. A.; KRIEGER, N.; BEROVIC, M. Solid-state fermentation bioreactors: fundamentals, design and operation. Springer-Verlag: Berlin, 2006.

MORETTI, M. M. de S. Isolamento de fungos termofílicos produtores de celulases, xilanases e ferruloil esterase para bioconversão de bagaço de cana de açúcar em açúcares fermentescíveis. 2010. 112f. Dissertação (Mestrado). Instituto de Biociências, Universidade Estadual Paulista "Júlio de Mesquita Filho", Rio Claro, 2010.

PINTO, T. O. P. Produção de Enzimas Celulolíticas pelos fungos Thermoascus aurantiacus CBMAI 756, Thermomyces lanuginosus, Trichoderma reesei QM9414 e Penicillium viridicatum RFC3 e Aplicação na sacarificação do bagaço de cana de açúcar com diferentes pré-tratamentos. 2010. 91f. Dissertação (Mestrado). Universidade Estadual Paulista, São José do Rio Preto - SP, 2010.

ROWELL, R. Handbook of wood chemistry and wood composites. Boca Raton: CRC Press, 2005. 487p.

SLAVIN, J. Why whole grains are protective: biological mechanisms. Proceedings of the Nutrition Society, v. 62, p. 129-134, 2003.

SONI, R.; NAZIR, A.; CHADHA B. S.; SAINI, H. S. Novel sources of fungal cellulases for efficient deinking of composite paper wast. Bioresources, v. 3, n. 1, p. 234-246, 2008.

ZANELATO, A.I.; SHIOTA, V.M.; GOMES, E.; THOMÉO, J.C. Endoglucanase production with the newly isolated Myceliophtora $s p$. I-1D3b in a packed bed solid state fermentor. Brazilian Journal of Microbiology, v. 43, n. 4, p. 1536 - 1544, 2012. 